ISSN: $1130-3743$

\title{
SOCIEDAD CIVIL Y EDUCACIÓN DE LA CONCIENCIA MORAL
}

\section{Civil society and education for moral awareness}

\section{Société civile et éducation de la conscience morale}

José Manuel TouRIÑán LÓPEZ

Universidad de Santiago de Compostela. Facultad de Ciencias de la Educación.

Departamento de Teoría e Historia de la Educación. Campus Sur, s/n. 15782

Santiago de Compostela. Correo-e: hejmtl@usc.es

Fecha de recepción: diciembre de 2003

Fecha de aceptación definitiva: marzo de 2004

BIBLID [(1130-3743) 15, 2003, 213-234]

RESUMEN

El sentido de lo social se ha enriquecido en nuestros días debido al carácter transnacional de las acciones globales. Ya no hablamos simplemente de derechos sociales que requieren la subsidiación del Estado con unos medios que no pertenecen a ningún individuo en particular; hablamos de derechos que reclaman la cooperación positiva de los Estados y la sociedad civil, más allá de las fronteras territoriales. Esto modifica el carácter de territorialidad del Estado y el sentido del compromiso de la sociedad civil.

Este nuevo desafío tiene que asumir las consecuencias de entender la transnacionalidad y la glocalización como condiciones inherentes de los derechos de tercera generación y esto exige replantear los problemas en la sociedad civil desde una ética que asume la realidad del otro y está elaborada a partir de la singularidad de las situaciones y la universalidad de los valores.

Palabras clave: sociedad civil, educación moral, educación intercultural, glocalización y transnacionalidad, legalidad y legitimidad, moral civil y ética cívica mínima, construcción social de la convivencia. 


\section{SUMMARY}

The meaning of "social" has been enriched nowadays due to the cross-cultural nature of global actions. We do not now simply refer to social rights under the State supervision with means that do not belong to any concrete individual. We talk about rights that require the positive co-operation of States and civil society, co-operation which surpass countries' boundaries. Indeed, this modifies the state belonging sense and the civil society's commitments.

This new challenge has to be able to manage the consequences of seeing both cross-culturalism and glocalism as inherent conditions of the third generation rights, and all of that requires rethinking the problems within civil society from an ethic scheme that understands "the other" and that is also based on the singularity of each situation and the universalisation of (human) values.

Key words: civil society, moral education, intercultural education, glocalism and cross-culturalism, legality and legitimity, civil moral and minimum civic ethic, living together social construction.

\section{SOMMAIRE}

Le sens de ce qui est social c'est enrichi dans nos jours, étant donné le caractère transnational des actions globales. Nous ne parlons pas simplement de droits sociaux qui requièrent l'allocation de l'État avec des moyens qui n'appartiennent à aucun individu en particulier; nous parlons de droits qui réclament la coopération positive des États et de la société civile, au-delà des frontières territoriales. Ceci modifie le caractère de territorialité de l'État et le sens du compromis de la société civile.

Ce nouveau défi doit assumer les conséquences de comprendre la transnationalité et la glocalisation comme conditions inhérentes des droits de troisième génération et ceci exige de remettre en question les problèmes dans la société civile depuis une éthique qui assume la réalité de l'autre et est élaborée à partir de la singularité des situations et l'universalité des valeurs.

Mots clef: société civile, éducation morale, éducation interculturelle, glocalisation et transnationalité, légalité et légitimité, morale civile et morale civique minimale; construction sociale de la coexistence.

\section{INTRODUCCIÓN}

Construir la convivencia es uno de los problemas fundamentales de nuestro mundo, desde muy diversas perspectivas. La educación de la conciencia moral es un objetivo imprescindible para afrontar esta tarea en la que la sociedad civil tiene un papel especialmente significativo. La manifestación más genuina de la acción 
moral en la sociedad civil es el desarrollo de la moral civil que cumple su función identificadora, conformadora y legitimadora de la vida social en convivencia.

La educación se configura como un factor de desarrollo sociomoral en el marco de la sociedad abierta multicultural y pluralista y la decisión del sujeto aparece, de este modo, como una cuestión de derechos y como una cuestión de compromiso ético que no opone autonomía y comunidad, con lo que se hace más evidente el sentido moral de lo social y el sentido social de la libertad.

El sentido de lo social se ha enriquecido en nuestros días, debido al carácter transnacional de las acciones globales. Ya no hablamos simplemente de derechos sociales que requieren la subsidiación del Estado con unos medios que no pertenecen a ningún individuo en particular; hablamos de derechos que reclaman la cooperación positiva de los Estados y la sociedad civil, más allá de las fronteras territoriales. Esto modifica el carácter de territorialidad del Estado y el sentido del compromiso de la sociedad civil.

Este nuevo desafío tiene que asumir las consecuencias de entender la transnacionalidad y la glocalización como condiciones inherentes de los derechos de tercera generación y, en el marco de los derechos de tercera generación, el juego del desarrollo no está en un equilibrio pactado entre los Estados para conjugar soberanía y subsidiariedad. Se ha cambiado el marco y el Estado no está por encima de las reglas de juego. La globalización, el pluralismo y los flujos migratorios constituyen el entramado desde el que hay que buscar la convergencia entre diversidad, interculturalidad e identidad localizada y esto exige replantear los problemas en la sociedad civil desde una ética que asume la realidad del otro y está elaborada a partir de la singularidad de las situaciones y la universalidad de los valores.

Con objeto de desarrollar esta propuesta, hemos formulado cuatro apartados en este trabajo que enfatizan respectivamente:

- La interculturalidad como meta en la sociedad civil.

- La convergencia entre diversidad e interculturalidad como compromiso global.

- El sentido social de la libertad como refuerzo de la conciencia moral.

- La sociedad civil como agente moral.

\section{2. ¿Propuesta MUliticUltURAL O INTERCULTURAL PARA LA SOCIEDAD CIVIL?}

Muy diversos estudios en torno al concepto de migración, ciudadanía, identidad, derechos, sociedad global, raza y etnicidad están abogando por la necesidad de reconceptualizar acerca de la alternativa multicultural-intercultural y permiten cuestionar, en parte, los resultados a los que nos han llevado la práctica de procesos de asimilación, segregación, integración y tolerancia multicultural de enclaves étnicos en Estados Unidos, Alemania, Francia e Inglaterra, respectivamente (Harcourt, 2003; Kleinwächter, 2003; Naval, 2003; Hallak, 2003; Lee, 2003). Los estudios antes mencionados buscan, de manera desapasionada, la respuesta 
intercultural — de encuentro a través de la educación—, en el desarrollo abierto de sociedades democráticas multiétnicas y pluralistas. La idea de fondo es llegar a entender que hemos estado utilizando conceptos cargados de inclusores que condicionan desfavorablemente el contexto social. En este sentido, nos dice Lee que el término "gente de color" o el término "diversidad cultural", por ejemplo, no tienden generalmente a incluir a aquellos que se autoidentifican como blancos. «Gente de color" implica que los blancos no tienen color en el uso ordinario del término. "Culturalmente diversos" implica que algunos grupos tienen algo singularmente cultural mientras que otros son simplemente humanos. Este modo de proceder implica, respecto de la interculturalidad, que algunos no tienen déficits culturales y no son sujetos del debate de inclusión o, alternativamente, exclusión (Lee, 2003; García Pastor, 2003).

Podemos afirmar, ateniéndonos a bases sociales y antropológicas, que a finales del siglo xx se acepta la permanencia de cinco fenómenos esenciales que condicionan el marco social para la construcción de la convivencia (García Carrasco, 1992):

- La intercomunicación de los grupos humanos propiciada por la expansión de los nuevos medios de comunicación.

- El resquebrajamiento de los patrones de identificación grupal y de referencia cultural como consecuencia de los movimientos interterritoriales.

- La inutilidad de la transferencia de modelos organizativos y estructurales de unos espacios a otros como garantía de progreso o de sostenimiento de nivel.

- La inexorable relatividad de los patrones de comportamiento de los grupos para alcanzar felicidad, coherencia y concordancia grupal.

- El papel de la heterogeneidad cultural en la identificación con grupos sociales de referencia.

En el año 1992 la Sociedad Española de Pedagogía promovió y organizó el $\mathrm{x}$ Congreso Nacional de Pedagogía bajo el título "Educación intercultural en la perspectiva de la Europa unidan (SEP, 1992). En palabras del presidente del Congreso, la sociedad europea tiende a una ideología apoyada en la consideración positiva de la diversidad, de tal manera que la educación tendrá que ser intercultural, es decir, potenciadora de la interrelación entre las diversas culturas en orden a garantizar un espacio cultural común sin renuncia a la identidad original (Orden, 1992).

En el año 1992 la búsqueda de soluciones a la multiplicidad de problemas de la educación intercultural se centraba en la idea de diversidad cultural y en la identidad; la educación era el camino adecuado para la integración intercultural. Las cuestiones fundamentales se vertebraban en torno a las preguntas (Orden, 1992):

- ¿Cómo potenciar el objetivo educacional de promover actitudes positivas hacia la diversidad cultural?

- ¿Cómo hacer que la educación sea un instrumento eficaz para integrar individuos de culturas diferentes en sistemas de valores y actitudes participadas? 
- ¿Hacia dónde tenderán las futuras políticas educativas de los países europeos en vías de integración?

- ¿Qué cambios se prevén como necesarios en la organización y dirección de los sistemas educativos nacionales para institucionalizar una educación intercultural?

El x Congreso Nacional de Pedagogía reconocía abiertamente que trabajar en contextos caracterizados por la diversidad cultural llevaba emparejado el doble compromiso de utilizar la diversidad cultural como recurso educativo y de fomentar valores fundamentales para el desarrollo del diálogo y la tolerancia. Tal compromiso exigía prácticas educativas interculturales tendentes a propiciar el cambio en las relaciones que tienen lugar en el seno de las escuelas y entre éstas y sus entornos sociales. Asimismo, en las conclusiones, se insistía en el riesgo intrínseco que supone acentuar el eurocentrismo como norma obligada para desarrollar un interculturalismo de carácter universalista (SEP, 1992).

Ahora bien, en nuestros días bay cuatro ideas que ban modificado el contexto de trabajo y de pensamiento respecto de la interculturalidad como hecho y del interculturalismo como propuesta:

- La idea de Tercer Sector que, junto con el Estado y el mercado, contribuye a regir los destinos del mundo desde las sociedades civiles como forma de organización (Salamon, 2001).

- La idea de Tercer Entorno que, junto con la vida rural y la vida ciudadana, configura nuevas posibilidades a través de la sociedad digital (Echeverría, 1999).

- La idea de Mundialización que, a partir del 11 de septiembre de 2001 con el atentado a las torres gemelas, ha empezado a modificar el sentido de la transnacionalidad, porque la seguridad ciudadana, el terrorismo internacional y la inseguridad jurídica alcanzan nuevas formas y consecuencias generales para la vida en el planeta (Castells, Giddens y Touraine, 2002).

- La idea de Tercera o Cuarta Vía que, bajo la propuesta de sociedad del conocimiento y de respeto al desarrollo sostenido, propugnan hacer frente a la globalización y a la transformación continua de la vida personal en el mundo moderno desde el triple objetivo del bienestar económico, cohesión social y libertad política (Giddens, 1999; Dahrendorf, 1995; Druker, 1993; Colom, 2000).

Las circunstancias actuales no son las del siglo pasado. En nuestros días se está creando un espacio mundial en el que las fronteras se hacen transparentes para los intercambios socioeconómicos y científico-culturales y se crean las condiciones necesarias para (Gómez Dacal, 2003):

- El resurgimiento de flujos migratorios atraídos por las posibilidades que ofrecen mercados laborales más ricos y desarrollados. 
- La aparición de una nueva clase social marginal, el cognitariado, voz con la que se nombra a quienes carecen los recursos cognitivos necesarios para el éxito en la sociedad del país de acogida.

- La posibilidad de creación de un sistema jurídico transnacional que ampara derechos que se establecen, haciendo abstracción del contexto histórico y cultural de cada pueblo bajo la bandera de los derechos universales del hombre.

El desafio del siglo xxi es el desafío de la mundialización, una "tierra-patria" de todos los humanos en la que las instancias de nivel internacional sean capaces de luchar contra los más graves peligros, sean estos peligros derivados de la globalización o del exacerbado sentido de localidad (Morin, 2002). Es obvio que, cuanto mayor sea la globalización -es decir, cuanto mayores sean los flujos de capital, de inversión directa y de tecnología que acuden a los países en desarrollo y cuanto mayor acceso tengan estos países por medio de sus exportaciones a los países ricos-, menores serán los flujos potenciales de inmigración; pero también es verdad que la globalización consiste en la posibilidad de grandes movimientos migratorios que permiten asignar más eficientemente la mano de obra en el mundo y reducir crecientes desigualdades (Dehesa, 2000). Tan cierta es esta reflexión que el sesgo radical, en palabras de Víctor Pérez Díaz, es la defensa de la libertad de las personas, que es el reto de la tradición occidental para todas las civilizaciones para que se reformen y evolucionen en esa dirección garantizando la oportunidad de salir del propio marco; es decir, promover un marco orientado a facilitar la creación de un mundo de "emigrantes potenciales" y, precisamente gracias a ello, un mundo de gentes capaces de resistir las formas despóticas de la autoridad pública de su propio país, sean estas autoridades políticas, sociales, económicas o culturales (Pérez Díaz, 2002; Valcárcel, 2002; Romay, 2002).

La globalización es el término con el que se hace referencia a los procesos en virtud de los cuales los estados nacionales soberanos se entremezclan e imbrican mediante actores transnacionales (organizaciones no gubernamentales, multinacionales, Naciones Unidas) en la sociedad mundial con sus respectivas probabilidades de poder, de orientación, de autoidentificación y también de cooperación al desarrollo. Así lo entiende el Fondo Monetario Internacional, que insiste en el carácter de proceso de acelerada integración mundial de las economías a través de la producción, el comercio, los flujos financieros la difusión tecnológica, las redes de información y las corrientes culturales (Dehesa, 2000).

Es un sentir común que existe una afinidad entre las distintas globalizaciones (económica, política, cultural y socioeducativa). Pero existe también la convicción de que esa pluralidad sin unidad de las globalizaciones hace que no sean reductibles unas a las otras, ni explicables unas por las otras (Berger y Huntington, 2002). Todas ellas deben entenderse y resolverse a la vez en sí mismas y en mutua interdependencia, de tal manera que, en el entorno de las tecnologías de la información y las comunicaciones, cada vez cobra más fuerza la propuesta de defender la existencia 
de sociedades del conocimiento en el mundo globalizado, frente a la existencia de la sociedad del conocimiento en ese mundo, pues parece evidente que la implantación de un modelo uniforme a escala planetaria no responde a la verdadera historia de nuestros tiempos, ni al sentido de la diversidad (SID, 2000; Gray, 2000). En palabras de Drucker, lo que sabemos hoy, o por lo menos intuimos, es que los países desarrollados están abandonando también cualquier cosa que pudiera llamarse "capitalismo". El mercado seguirá siendo el integrador efectivo de la actividad económica; pero, en tanto que sociedad, los países desarrollados se han desplazado ya al poscapitalismo. En éstos, el factor de producción absolutamente decisivo ha dejado de ser el capital o el suelo o la mano de obra; ahora es el saber. El valor en la nueva sociedad se crea mediante la innovación y la productividad; ambas son aplicaciones del saber al trabajo y esa relación con el conocimiento favorece el carácter abierto de la sociedad del conocimiento (Drucker, 1993; Lessnoff, 2001; Popper, 1981; Dahrendorf, 2002).

Asumiendo con Stiglitz que la globalización puede ser una gran oportunidad, siempre que esté enmarcada por reglas que sean justas y equitativas, pues ése es el alegato central de su obra El malestar de la globalización que denuncia la política antisocial del Fondo Monetario Internacional (Stiglitz, 2002), conviene insitir en que, desde la perspectiva pedagógica, se destacan, cuatro rasgos en la globalización:

- Es un proceso de interpenetración cultural, rasgo que lo diferencia de las relaciones internacionales.

- Es un hecho inevitable que, en tanto que proceso histórico, se orienta hacia el futuro.

- Es un fenómeno que se singulariza por su extensión, su ritmo acelerado de crecimiento, la profundidad de su impacto y su carácter multidimensional.

- Es un sistema complejo con dimensiones interconectadas en el que las redes de información, los flujos migratorios y financieros y las corrientes culturales tienen un lugar específico.

En palabras de F. Altarejos, estas últimas - las corrientes culturales- bullen tanto como los intercambios comerciales y los flujos financieros, no sólo en lo que se refiere a los movimientos migratorios que ponen el interculturalismo en el primer plano de la dinámica social. También se va desarrollando, sutil y discretamente, pero de modo constante y creciente, un proceso interno de revisión cultural -que es de verdadera inculturación en muchos países-; proceso en el que se ponen de manifiesto y se acentúan las notas propias de las comunidades, al tiempo que se perciben más vívidamente las influencias ajenas en la configuración de la sociedad. Precisamente por eso, mantiene el profesor Altarejos que

la globalización puede definirse también, y no de modo secundario y derivado, como el proceso de creciente intercomunicación de las culturas. De este modo, al impregnar todas las dimensiones de la sociedad, tanto en su dinámica interna como en su proyección externa a las relaciones internacionales, la globalización es el fenómeno que mejor caracteriza el mundo actual. Se puede ser más o menos 
consciente de ello; se puede estar razonablemente orientado o torpemente confundido respecto de su sentido; pero es imposible ignorar el nuevo rumbo que marca al futuro del mundo (Altarejos, 2003, 16).

En nuestros días, podemos decir que la multiculturalidad es una característica del contexto que rodea a la interculturalidad como una meta acorde con los nuevos tiempos en que vivimos (Sarramona, 1999 y 2002). Éste es un postulado que se mantiene como consecuencia de la mundialización, de la transnacionalización y de las posiblidades de defensa de la diversidad cultural en un mundo globalizado que entiende el papel del conocimiento en el desarrollo. Ahora bien, ni el multiculturalismo, ni el interculturalismo constituyen una mera constatación de la enorme multiplicidad de etnias, lenguas y culturas y de los estilos a seguir en ese contexto ideológico. El multiculturalismo y el interculturalismo son proyectos con carga ideológica, pues se trata de lo que queremos fomentar y defender. En este sentido, mientras que el interculturalismo profundiza en la idea de la convivencia y el avance de la penetración cultural, el multiculturalismo, en palabras de Sartori, se contrapone al pluralismo y hace prevalecer el efecto de la separación sobre la integración o la inclusión, porque entiende que las diferencias deben ser discriminadas positivamente, no por su valor, sino por el simple hecho de existir, lo cual quiere decir, desafortunadamente, que el multiculturalismo debe aceptar proteger y fomentar las diferencias con independencia de su valor intrínseco y evitar la evolución natural del choque de civilizaciones o culturas (Sartori, 2001).

Y así las cosas, estamos convencidos, no sólo de que la educación sigue siendo el camino adecuado para la integración intercultural, sino también de que las nuevas ideas que configuran el contexto de trabajo y pensamiento, fortalecen la firme convicción de que un proyecto de voluntades, y no sólo de derechos, ampara la propuesta de marco intercultural para la sociedad civil, pues el sentido de la globalización y de la mundialización refuezan la perspectiva pedagógica de la interpenetración cultural.

\section{LA PROPUESTA GLOCAL COMO CUESTIÓN DE DERECHOS Y COMPROMISO ÉTICO}

Los dispositivos de comunicación, en la misma medida que han ampliado el ámbito de circulación de las personas, bienes materiales y símbolos, han acelerado el proceso de desplazamiento de fronteras físicas, mentales y culturales. Las carreteras, en un primer momento, el ferrocarril y las autovías, en un momento posterior, y las autopistas de la información, en nuestros días, simbolizan, como propuesta, el acceso a un mundo mejor de carácter solidario que puede ser construido como resultado de la acción orientada del hombre. La realidad es que, en cada caso, ese ideal de progreso tecnológico no ha podido evitar la distorsión entre la tendencia a la homogeneidad tecno-económica internacional y el deseo de afirmación de la identidad, incluso siendo ciudadanos del mundo en la sociedad global. Esta distorsión marca el resultado del camino emprendido hacia la integración 
y la interculturalidad en los programas de tendencia hacia la descentralización. Cualquier estrategia de desarrollo en este mercado global tiene que ser a la vez global y local, porque lo local, lo regional, lo nacional y lo internacional no son espacios desconectados, sino espacios unidos por el carácter glocal (Matelart, 1998; Touriñán, 1999 y 2000; Borja y Castells, 1999).

Es un hecho innegable que los dispositivos de comunicación, en la misma medida que han ampliado el ámbito de circulación de las personas, bienes materiales y símbolos, han acelerado el proceso de desplazamiento de fronteras físicas, mentales y culturales.

Las geofinanzas y sus espacios abstractos desterritorializados constituyen un ejemplo claro de la cibereconomía en un mundo globalizado; se trata, en este contexto, de poner, por delante de la producción y la inversión industrial, la función financiera y el movimiento especulativo de capitales en tiempo real en un marco territorial global que desborda los límites territoriales sobre los que se asienta la soberanía de los Estados. Se ratifica, como ya decíamos, que cualquier estrategia en el mercado global tiene que ser glocal; es decir, a la vez global y local, porque lo local, lo regional, lo nacional y lo internacional no son espacios desconectados (Mattelart, 1998; Heilbroner, 1998).

Con el advenimiento de la sociedad de la información y la globalización cualquier elemento cultural, pensamiento, palabra o acción puede traspasar fácilmente las fronteras del territorio en el que se produce. Cualquier acontecimiento, por local que sea, puede convertirse en un acontecimiento global, al que tengan acceso los ciudadanos del mundo, por lo menos los de los países desarrollados. El sentido transnacional de la cultura y la cooperación en el mundo globalizado de la sociedad de la información cambia el marco territorial restringido de la sociedad predigital (Pérez Díaz, 1997; Pérez Serrano, 1999; Touriñán, 2002; Touriñán, Rodríguez y Soto, 2000).

La conocida distinción entre formas residuales, dominantes y emergentes de cultura es un buen reflejo de lo que queremos enfatizar en el párrafo anterior y que Samuel Huntington ha expresado de manera personal y acertada como "choque de civilizaciones", pues la influencia de la cultura en la política y en la economía varía de unos períodos a otros y es especialmente fuerte en el mundo posterior a la Guerra Fría. En la fase actual de la historia global todo parece apuntar, en palabras de Huntington, a que las causas fundamentales de conflicto internacional son de carácter cultural en el sentido de que las diferencias importantes entre civilizaciones en materia de desarrollo político y económico están claramente enraizadas en sus diferentes culturas. Las grandes divisiones de la humanidad a partir de los años noventa del siglo xx no son los tres bloques de la Guerra Fría, sino los agrupamientos correspondientes a las civilizaciones principales del mundo (occidental, latino-americana, africana, islámica, sínica, hindú, ortodoxa, budista y japonesa). La cultura y las identidades culturales están modelando los patrones de cohesión, desintegración y conflicto en el mundo actual. En este mundo del siglo xxi la política local es la política de la etnicidad; la política global es la 
política de las civilizaciones. El choque de civilizaciones reemplaza a la rivalidad entre las superpotencias. La política global se ha vuelto multipolar y multicivilizacional (Huntington, 2001).

La globalización, el pluralismo y los flujos migratorios constituyen el entramado desde el que hay que buscar la convergencia entre diversidad, interculturalidad e identidad localizada, porque la tensión entre la defensa de la propia comunidad y el imperativo de mundialización fuerza a los individuos a enfrentarse a la vez con una alteridad reducida y una alteridad que crece exponencialmente y esto exige replantear los problemas desde una ética elaborada a partir de la singularidad de las situaciones y la universalidad de los valores (Abdallah-Pretceille, 2001).

La encrucijada, en palabras de Gonzalo Vázquez, exige abrazar tres niveles de referencia existencial para el hombre - su propia identidad personal, su tierra y su horizonte interrogativo e interpretativo del sentido de la realidad y de la existencia-, y, así las cosas, cada individuo afronta como reto la convergencia de pensamiento, palabra y acción, de manera que se puedan salvar los límites de lo universal, de lo próximo ambiental y de lo singularmente personal (Vázquez, 1994).

En perspectiva evolutiva de la búsqueda constante, al entorno social le corresponde asumir que el diálogo entre culturas plantea problemas de convivencia, que nacen del contacto entre grupos étnicos distintos, y problemas de supervivencia, que se acentúan con la distancia entre el norte y el sur (Puig, 1992). Conviene no olvidar en este sentido que la centralidad de Internet en muchas áreas de la actividad social, económica y política se convierte en marginalidad para los que no tienen o tienen acceso limitado a la red, así como para los que no son capaces de sacarle partido, acrecentándose, de este modo, la divisoria digital desde una perspectiva global (Castells, 2001; García Carrasco, 2002). Pero, además, como dice el profesor Escámez, el diálogo entre culturas produce problemas morales, porque las personas en conflicto cultural son capaces del menosprecio, la xenofobia y el racismo. Hay un compromiso obligado de aunar voluntades para no desestructurar la comunicación, como consecuencia de obviar el triple reconocimiento que se le debe al individuo en el marco social (ético-personal, étnico-cultural y cívico-jurídico), que nos obliga a defender la interculturalidad como proyecto ético (Escámez, 1992 y 1999; Martínez y Puig, 1991; Roma, 2001).

Las ONG's representan una aspiración a otro tipo de espacio mundial, debido a la concepción que conllevan en sus áreas de intervención respecto de la democracia en la vida cotidiana (Touriñán y Santos, 1999). Con todo, resultaría aventurado afirmar que estamos asistiendo de manos de las onG's al advenimiento de una nueva sociedad civil internacional, pues no debemos olvidar que, salvo que se acepte el mito del fin del Estado - lo cual se acomodaría muy bien al mito de la república mercantil universal que propicia el globalismo-, el marco territorial delimitado sigue siendo el lugar de construcción de la ciudadanía (Mattelart, 1998). En cualquier caso, al Tercer Sector (ONG's y fundaciones) les corresponde asumir un protagonismo especial, construyendo el futuro, junto con el mercado y las administraciones, pues es obvio que el Tercer Sector no tiene intereses de Estado más 
allá de las ideas de derechos de tercera generación, sociedad civil, cooperación al desarrollo, solidaridad internacional y diversidad cultural.

La Fundación BBVA ha publicado en el año 2001 un libro que recoge 22 de más de cuarenta trabajos que componen la investigación original llevada a cabo por L. M. Salamon y sus colaboradores sobre el sector civil global, con objeto de dar a conocer las dimensiones aproximadas del sector no lucrativo - Tercer Sector-, que no se confunde con el concepto de Tercer Entorno que Echeverría definió como el espacio social electrónico (Salamon, 2001; Echeverría, 1999). Resulta sorprendente constatar que, desde un punto de vista comparado, transnacional, pocos tipos de organizaciones han recibido menos atención por parte de los científicos que las fundaciones filantrópicas. Salvo en su aspecto legal, las fundaciones no han sido analizadas desde el punto de vista de su estructura, gestión y evolución histórica (Domínguez y otros, 2001; Lorenzo y Cabra, 1991). Paradójicamente, los representantes de intereses empresariales y cívicos acentúan el papel y protagonismo de las fundaciones para construir la sociedad civil y prestar servicios a la sociedad, pues las fundaciones son un instrumento eficaz desde el punto de vista de la creación de actividad cultural para acrecentar la cooperación entre sector público, sector privado y sector no lucrativo.

Esta aproximación general realizada en los parágrafos anteriores, tiene como objeto introducirnos en las diferentes formas de racionalidad en la toma de decisiones, teniendo en cuenta que la sociedad civil actual (el Tercer Sector no lucrativo que se distingue del Estado y del mercado mundial - los otros dos sectores-) tiene un papel de singular importancia en la promoción y fomento de la cultura que debe ser gestionada con criterios de profesionalidad y con sentido de responsabilidad institucional compartida, porque la cultura no es competencia exclusiva de ninguna institución y tiene, carácter público y social que se ha reforzado con la defensa de la diversidad y la inclusión como derechos de tercera generación (Touriñán, 1997 y 1979; Touriñán y Santos, 1999; Salamon, 2001; Pérez Díaz, 1993, 1997 y 1996; Pérez Serrano, 1994 y 1999; Cortina, 1995 y 1998; Brunkhorst, 1995).

Tenemos que ahondar en las exigencias singulares del compromiso institucional con la oferta cultural en nuestra sociedad, dado que la construcción compartida de la cultura a través de las redes en las sociedades del conocimiento es un problema de futuro que tenemos que atender con imaginación y profesionalidad. El Tercer Sector, como servicio a la sociedad y la cultura, se orienta, cada vez más, hacia el mundo exterior y asume una cuota de responsabilidad compartida en el desarrollo tecnológico y cultural, que exige planificación y gestión estratégica ajustada a la demanda (Ferguson, 1974; Mayor Zaragoza, 1993).

Las sociedades del conocimiento están obligadas a modificaciones globales en sus organizaciones (Attiná, 2001). Estamos obligados a plantear las viejas dificultades como nuevos retos con la firme convicción de que la cuestión no es un problema de nuevos medios y más medios, sino más acertadamente un problema de nueva organización, porque también las organizaciones tienen que estar a la altura de los tiempos. El sentido público de la acción cultural, el sentido polisémico de 
"Cultura" y la racionalidad de la toma de decisiones exigen racionalizar el modelo de decisión en la oferta cultural, atendiendo a criterios de (Touriñán, 2002):

- Idoneidad sociocultural.

- Oportunidad organizativa.

- Coherencia ideológica institucional.

Pertinencia, relevancia, eficacia, eficiencia, orientación estratégica y transparencia son indicadores básicos de decisión respecto de la oferta cultural que se puede compartir (Touriñán, 2002). La transparencia es el referente semántico de la coherencia como compromiso moral institucional en el ámbito de la cultura. Se dice de dos cosas que son coherentes cuando están relacionadas entre sí, y especialmente cuando están relacionadas entre sí de acuerdo con algún patrón o modelo. Desde el punto de vista de la lógica, la coherencia implica compatibilidad (entre oferta cultural elaborada e ideología de la institución). A su vez, la compatibilidad expresa conformidad de una propuesta a una regla o criterio.

Resulta obvio afirmar que la coherencia ideológica institucional respecto de la oferta se traduce en la concreción de las misiones y metas cualitativas que conforman la idoneidad sociocultural de la oferta cultural propuesta; pero no resulta tan obvio afirmar que la coherencia se está vinculando cada vez más al cumplimiento y declaración pública de compromiso con un código deontológico de la institución respecto de la promoción, gestión y creación cultural. En este sentido, la coherencia no es tanto un problema de idoneidad sociocultural o de organización racionalizada - que también exige coherencia-, como un problema de orden moral y de compromiso público de la institución con la cultura y con el servicio al interés general social.

Se comprende, desde esta perspectiva, que la Unesco, en su estudio detallado y programático acerca de la diversidad creativa que fue realizado por la Comisión Mundial de Cultura y Desarrollo, proponga las siguientes claves conceptuales para la formulación y orientación de las misiones y metas de las instituciones que promuevan actividades culturales (Unesco, 1997):

- Aceptar la diversidad creativa.

- Favorecer el capital humano.

- Fomentar la innovación productiva.

- Impulsar la cooperación al desarrollo.

- Respetar la identidad cultural y la multiculturalidad.

- Promover la interculturalidad y la integración cultural.

- Apoyar los canales tecnológicos de comunicación e información para el crecimiento de la cultura.

- Generar redes culturales.

- Promover la creación de futuro en los diversos ámbitos de actividad creativa.

- Destacar la singularidad de cada una de las acciones creativas. 
Pero se comprende, además, que el sentido de la propuesta glocal nos lleva a pensar en el individuo como ser capaz de combinar la cultura universalizada y la circundante, realizando "desplazamientos" de una a otra sin problemas, porque su yo multifacético está inevitablemente abierto a influencias procedentes de fuera de su contorno. La cuestión no es el derecho a una cultura universal, sino el derecho a combinar libremente la experiencia personal y colectiva bajo la garantía de reservarse el derecho de entrar y salir en cada oportunidad cultural (Pérez Díaz, 2002; Dahrendorf, 2002; Gimeno, 2001).

El conflicto y las confrontaciones pueden surgir, cuando se produce un choque cultural entre dos o más culturas en contexto glocal. Es un hecho que la educación debe formar para la convivencia y educar para el conflicto (Ortega, Mínguez y Saura, 2003; Consejo Escolar del Estado, 2001; SITE, 2001). Sin embargo, la carga a favor del problema como problema de voluntades, no debe hacernos olvidar que el problema analizado es de manera prioritaria también un problema de legitimidad. Hoy en día se mantiene que el siglo xxi no será el siglo del poder ejecutivo, ni del poder legislativo; será preferentemente el siglo del poder judicial. Si esto es así, es legítimo preguntarse, frente a la inmigración o a la invasión cultural: ¿Con qué derecho se exige un derecho nuevo de una minoría cultural en un territorio de acogida que puede conculcar derechos reconocidos constitucionalmente en ese territorio? (SITE, 2002; Olveira, Rodríguez y Touriñán, 2003; Valcárcel, 2002). La propuesta glocal afecta a cada individuo y la decisión del sujeto aparece, de este modo, como una cuestión de derechos y como una cuestión de compromiso ético, con lo que se hace más evidente el sentido moral de lo social y el sentido social de la libertad.

\section{EdUCACIÓN Y SOCIEDAD. El REFUERZO DE LA CONCIENCIA MORAL}

La educación se configura como un factor de desarrollo sociomoral en el marco de la sociedad abierta multicultural y pluralista, porque (Hallak, 2003):

- La educación es elemento fundamental para el éxito de la integración en un mundo que reclama competencias específicas para "aprender a ser", "aprender a hacer", "aprender a aprender" y "aprender a vivir juntos".

- La educación es uno de los instrumentos más eficaces para promover y proteger la identidad cultural.

- La educación es la vía adecuada para conseguir personas autónomas capaces de defender y promover los derechos en un mundo globalizado.

Precisamente por eso, conviene insistir, con el profesor P. Ortega en que:

La escolarización ha situado a la educación intercultural en el ámbito de lo cognitivo como si se tratara de conocer, comprender y respetar las ideas, creencias, tradiciones y lengua de una comunidad; en una palabra, la cultura del otro, haciendo abstracción o relegando a un segundo plano al sujeto concreto que está detrás de 
esa cultura. Han primado más los aspectos culturalistas que los antropológicos y morales. Y la educación intercultural no se agota en el respeto a la cultura del otro, sino que debe llevar, además, a la aceptación y acogida de su persona (Ortega, 2001, 71).

Estamos convencidos de que el fortalecimiento de esta tendencia hacia la comprensión y aceptación del otro está en el origen del sentido más básico de la relación entre la libertad y lo social, problema al que le hemos dedicado atención en otros trabajos y que ahora resumimos en sus tesis fundamentales para mantener el hilo del discurso (Touriñán, 1979).

En nuestra opinión, no es correcto entender la libertad como un concepto abstracto que rechazara toda aceptación de limitaciones. El autonomismo, como cultivo del yo sin el otro, es una extravagancia que nos lleva a fomentar irracionalmente una actitud francamente opuesta a lo social, como si el problema de la maduración de la libertad pudiera plantearse con una total indiferencia a la cuestión de si esa misma libertad se da en los demás.

Hay un fundamento moral en el sentido de lo social que nos hace comprender que la autonomía no se pierde por hacer realidad lo social, a menos que lo social se rodee de notas improcedentes. La libertad y lo social se reclaman, no sólo de un modo más o menos conveniente, sino de un modo esencial y de un modo - también podemos decirlo así- libre. Tan cierto es que lo social está en el hombre y ante él mismo, sin pedirle su consentimiento, como que lo social no se realiza plenamente en cada hombre, si él no le da su libre aquiescencia.

En consecuencia, es un objetivo básico de la Pedagogía hacer comprender que la educación, entendida en su sentido pleno, no alcanza su objetivo con desarrollar un hombre capaz de valerse por sí mismo y para sí mismo. Además, debe entenderse que este núcleo personal no estará conseguido mientras que la educación no salvaguarde y cultive en cada educando los principales derechos y obligaciones que como ciudadanos y como miembros de la comunidad deben cumplir.

Se acepta que lo social existe, porque el hombre tiene relación con los demás, pero también se acepta que a esta dimensión no se le concedió entidad por sî misma en cualquier época y, por supuesto, en ninguna de las épocas que se le había dado importancia alcanzó un grado de preponderancia semejante al que hoy tiene.

Arendt nos dice que las esferas pública y privada existen como entidades diferenciadas y separadas al menos desde el surgimiento de la antigua ciudad-estado en la cual dichas esferas se correspondían con el campo político y familiar. Desde esa época, con mayor o menor rigor, se ha mantenido que lo privado hace referencia a las personas en sí mismas o a sus bienes y lo público concierne a las misiones y relaciones de las personas con el Estado o a las relaciones de los Estados entre sí. Arendt viene a decirnos que la dimensión social toma carácter jurídico con el Estado Moderno. El auge de lo social coincidió históricamente con la transformación del interés privado por la propiedad privada en un interés público. La sociedad adoptó el disfraz de una organización de propietarios que, en lugar de 
exigir el acceso a la esfera pública debido a su riqueza, pidió protección para acumular más riqueza. O sea, que lo social vendría a expresar un ámbito nuevo que no consistía en una situación puramente privada -que cada hombre, por ejemplo, obtenga los frutos que sus medios le permiten-, ni en una situación puramente pública —el modo de elegir el Gobierno, por ejemplo-, sino en una situación especial: que cada hombre alcance de manera más completa un bien privado con unos medios que no le pertenecen a él exclusivamente (Arendt, 1974).

Y así las cosas, jurídicamente hablando, aunque sabemos que una actividad concreta puede pasar de una de las esferas a las otras, también sabemos que, mientras la dimensión privada se refiere a las personas y a sus bienes particulares, y la pública se refiere a las relaciones formales entre Estados o de las personas con el Estado, la dimensión social se refiere a aquellas situaciones que afectan al individuo, pero que no podrían producirse más que en la sociedad organizada, pues se favorece el bien privado de cada uno con unos medios que se alcanzan con la ayuda que, directa o indirectamente, nos proporcionan los demás.

No cabe duda, entonces, de que la libertad tiene carácter social, porque es un bien privado cuya posesión de manera completa - como libertad moral - la logra cada persona con unos medios que no son suyos, porque lo social se refiere a las acciones en que, de un modo u otro, interviene la reciprocidad, en que no sólo yo soy centro emisor de acciones hacia mí, sino que en mi acción tiene que estar ya anticipada la del otro, es decir, se cuenta con la suya; o sea, que los dos actuantes se responden mutuamente, se corresponden (Touriñán, 1979).

Lo social, si no se tergiversa su sentido, hace referencia a aquellas situaciones de relación entre las personas, a aquellas situaciones de reciprocidad en las cuales se pretende que cada hombre pueda alcanzar de modo más completo su bien privado con unos medios que no le pertenecen exclusivamente. En estas situaciones, todos tenemos que ordenar intencionalmente nuestras disposiciones para cumplir los derechos y obligaciones que nos atañen a fin de que lo social se realice correctamente.

Pero, precisamente porque tenemos que dar una respuesta libre a esa situación, comprobando en qué medida yo o los demás nos convertimos en un obstáculo para el ejercicio de la libertad, o en qué medida realizamos lo social, nuestra respuesta puede convertirse en un estímulo social al que los demás tienen que responder.

Si tenemos en cuenta que ningún estímulo social nos marca de forma incondicionalmente eficaz el modo de satisfacerlo, ya que, metafísicamente hablando, ninguno de esos usos concretos es absolutamente bueno y, psicológicamente hablando, entre el estímulo y la respuesta se encuentra la actividad del sujeto, de tal modo que, al menos, la decisión de realizarlos, el qué a que obedece esa decisión y el modo de llevarlos a efecto son cosas de la vida auténticamente personal, se explica la existencia posible de personas insociables, que soportan a los demás, pero carecen de las condiciones que los hacen aptos para la convivencia, y de personas antisociales, que llevan a la práctica sus tendencias en contra de los demás.

Se sigue, por tanto, que el hombre tiene que dar respuesta a unos estímulos sociales que no le determinan ni son perjudiciales incondicionalmente. Puede dar 
una respuesta, haciendo uso exclusivo de su libertad estrictamente psicológica; en este caso, bien se limita a utilizar arbitrariamente estos estímulos en contra de los demás, convirtiéndose en un ser antisocial, o bien se dedica a seguir aquellos que le interesan sin otra norma que los dictados de su capricho, convirtiéndose en un ser insocial, o bien se contenta con seguir ciegamente todos los dictados de los usos vigentes, transformándose en un hombre masificado. Pero también puede hacer uso de su libertad moral y actuar éticamente.

El fundamento moral de lo social nos hace comprender que la encrucijada social de la libertad surge porque el hombre necesita a los demás para alcanzar el recto uso de su libertad, pero tan cierto es que nos es precisa la sociedad y nos encontramos en ella inevitablemente, como que la sociedad no puede cumplir su misión social si nosotros no le damos nuestra libre aquiescencia. Se trata, en definitiva, de dar cuerpo a la idea de responsabilidad moral como construcción en la que el agente no opone autonomía y comunidad, porque sabe que en la realización de los mismos procesos de relación intersubjetiva -de inmersión en el medio- se constituye a la vez la individualidad autónoma y se reproduce el mundo de la vida comunitaria (Puig, 2003).

\section{LEgAlidAD Y LEGITIMIDAD. LA SOCIEDAD CIVIL COMO AGENTE MORAL}

El término "sociedad civil" ha sido objeto de muy diversos estudios y tengo para mí que su uso licencioso ha generado ambigüedad contextual y semántica. Hoy hablamos de "sociedad civil socialista" y de "sociedad civil liberal", con la misma convicción que hablamos de "sociedad civil internacionalista" (Díaz-Salazar, 2002; Anheier, Glasius y Kaldor, 2002; Cohen, 1999; Vidal, 2002; Alvira, Grimaldi y Herrero, 1999). En el contexto de los epígrafes anteriores, para nosotros, tiene sentido hablar de "sociedad civil global", "sociedad civil transnacional" y "Sociedad civil mundializadaw. Ahora bien, en el contexto de este trabajo, conviene insistir con el profesor Escámez, en que el significado de "sociedad civil" es un asunto complejo ya que, para algunos, tal expresión se refiere a las instituciones, asociaciones, grupos o individuos en cuanto tienen intereses y actividades complementarias o contrapuestas a las de las instituciones del Estado. Para otros, sociedad civil y ciudadanía son términos de significado equivalente en cuanto se refieren a individuos e instituciones cuyos derechos o deberes están garantizados o exigidos por las leyes de un Estado. Precisamente por eso, conviene no olvidar que, en cualquier caso, cuando hablamos de construir la sociedad civil, estamos significando la creación y funcionamiento de instituciones y asociaciones a través de las cuales los hombres y las mujeres participan en los asuntos de la sociedad; de tal manera que lo que caracteriza a la sociedad civil es la participación y la responsabilidad de sus miembros en los asuntos sociales mediante diversas y plurales organizaciones (Escámez, 2003). 
El sentido de lo social se ha enriquecido en nuestros días, debido al carácter transnacional de las acciones globales. Ya no hablamos simplemente de derechos sociales que requieren la subsidiación del Estado con unos medios que no pertenecen a ningún individuo en particular; hablamos de derechos que reclaman la cooperación positiva de los estados y la sociedad civil, más allá de las fronteras territoriales. Esto modifica el carácter de territorialidad del Estado y el sentido del compromiso de la sociedad civil.

Tengo para mí que este nuevo desafío tiene que asumir las consecuencias de entender la transnacionalidad y la glocalización como condiciones inherentes de los derechos de tercera generación. En el marco de los derechos de tercera generación, el juego del desarrollo no está en un equilibrio pactado entre los Estados para conjugar soberanía y subsidiariedad. Se ha cambiado el marco y el Estado no está por encima de las reglas de juego. Son unas nuevas reglas de juego en las que Estado, sociedad civil y el mercado son corresponsables del desarrollo mundial.

Estamos convencidos de que es un reto ineludible afrontar estrategias de encuentro a través de la educación, porque la brecha radical estriba en que no se asume en su sentido pleno el nuevo papel de la sociedad civil que en su mayoría de edad hace valer su fuerza transnacional en los foros mundiales con el apoyo de las redes digitalizadas. El encuentro se favorece si se propician principios de cooperación a favor de la justicia y del reconocimiento del otro a través de la educación.

En las sociedades abiertas y pluralistas hay un limite a la elasticidad de la tolerancia que nos obliga a definir y a decidir entre dos valores: el valor de la diversidad de la cultura y el valor de la igualdad de los derechos de todos. La decisión pedagógica en este caso es clara. La escuela debe asumir su responsabilidad cívica. Ya no basta con promover la adhesión al sistema y valores democráticos. Se precisa, sobre todo, impulsar una ciudadanía activa que se sienta parte en la permanente construcción de la sociedad democrática (Jover, 2000). El derecho a la educación se refiere, por tanto, a un ser situado, pero también a un sujeto con capacidad de distanciamento desde y sobre los condicionamientos culturales.

Más allá de ciertos significados históricos, el ethos de la subsidariedad se configura hoy como un compuesto de iniciativa y solidaridad. Es el ethos de una sociedad en la que se prima la iniciativa de abajo hacia arriba, en la que el protagonismo lo adquieren los ciudadanos. Pero es también el ethos de una sociedad para la que resulta una condición necesaria el apoyo a los más débiles y desfavorecidos (Jover, 2002, 19).

Se confirma, como decíamos al principio, la importancia de la creación de un sistema jurídico transnacional que ampara derechos que se establecen, haciendo abstracción del contexto histórico y cultural de cada pueblo, bajo la bandera de los derechos universales del hombre. En este contexto transnacional no me cabe duda de que la sociedad civil es un agente moral, porque tiene un papel singular respecto de la salvaguarda del fundamento ético del Estado de derecho y del cumplimiento del "código de conducta transnacional" $o$ de "ética mínima" que acentúa y justifica la "moral 
civil" para la defensa de los derechos, cualquiera que sea el territorio o la cosmovisión social, religiosa, ideológica, o política (Cortina, 1994; Medina, 1998; Varios, 1998; Touriñán y Santos, 1999).

A la vista del contexto internacional, no es discriminación racial la política que distingue entre derechos de los ciudadanos y no ciudadanos, ni la que limita o regula la concesión de ciudadanía. Limitar los derechos de la inmigración no está proscrito por ninguna norma internacional, ni viola los convenios que condenan la discriminación racial. Para nosotros, está claro que el derecho de propiedad, de identidad y de soberanía constituyen un entramado tan sólido y fundamentante en nuestra Constitución como el derecho a la educación y la cultura, y parece obvio que, si alguien, invocando cualquier idea "superior", nos quiere imponer directa o indirectamente a través de los mecanismos coactivos del Estado, un nivel de sacrificio colectivo que no consideramos adecuado, ese alguien habría vuelto al vulgar y recurrente "fundamentalismo" (Otero Novas, 2001).

El problema de la limitación legal afecta a la sociedad civil en su función de agente moral, porque la legislación dictada para una sociedad tiene como función general regular el comportamiento de las personas que integran la comunidad. En cuanto miembros de la comunidad, como ciudadanos, tenemos cauces legales para apoyar u oponerse a una posible legislación. Al fin y al cabo, legalidad significa, en el sentido más amplio y general, la existencia reconocida por el Estado para regular la vida de la comunidad de las leyes que, se quiera o no, afectan a los individuos en la misma medida que sus decisiones y actos quedan identificados en el contenido de las mismas.

Lo ideal sería que la legalidad y la educación coincidieran siempre con lo que es valioso para el desarrollo del hombre, pero no menos cierto es que mantener la vigencia de ese principio en cada ocasión equivale a olvidar que existe el error, que la sociedad no es homogénea y que podemos ocultar las razones que, siendo correctas, se oponen a nuestros deseos para esgrimir aquellas otras que, con independencia de su rigor lógico y justicia, los apoyan. Pero la ética y la ley no coinciden absolutamente en toda ocasión, como lo demuestra, entre otras cosas, la existencia de leyes injustas, por un lado, y, por otro, la incontestable experiencia de que las leyes de un Estado - que son humanas- no evitarían el problema moral individual de tomar decisiones y realizar actos que están identificados en el contenido de la ley, a menos que errónea y deshumanizadoramente las leyes anulen todo grado de libertad.

La encrucijada moral de la sociedad civil ante la ley es insoslayable, porque lo legal y lo moral apuntan desde sus propios ámbitos - no siempre coincidentesa la regulación de la libertad personal, y, consiguientemente, una sociedad sin normas legales sería terrible, porque, siendo la realidad interna y externa limitada, la ausencia de normas haría imposible la convivencia y favorecería el choque de los intereses de cada individuo con los de los demás; pero una sociedad sin más normas que las legales no sería digna del hombre, porque el absoluto imperio de la legalidad implica que la ley decidiría en lugar de los hombres. En una sociedad 
abierta y pluralista la encrucijada ante la legalidad supone básicamente resaltar el fundamento ético de todo Estado de derecho, pues el progreso de la legalidad en un Estado de derecho no excluye ni impide, empero, otro necesario progreso en el ámbito de la moralidad y de la justicia.

Legalidad y moralidad no van necesariamente unidas. Lo que está legalmente permitido no se identifica absolutamente con legalmente obligado, porque la ley respeta la libertad personal. Tampoco se identifica con moralmente obligado, porque, entre otras cosas, legal y moral no cubren el mismo ámbito. Y tampoco - ya por manipulación, ya por el propio carácter participativo de la legislación pluralista- es coincidente con moralmente permitido en todos aquellos casos en que "legal" y "moral" afectan al mismo objeto (Touriñán, 1983).

Incluso existiendo coincidencia entre la legalidad y la moralidad en un tema concreto, el éxito no queda establecido en ese caso cuando la legislación favorece una respuesta ciudadana legalmente irreprochable, sino cuando, además, se respeta la libertad; es decir, el sujeto que da esa respuesta comprende y acepta las razones que la justifican. Precisamente por eso, la manifestación más genuina de la acción de la sociedad civil como agente moral, es la moral civil, que cumple una función identificadora, conformadora y legitimadora de la vida social en convivencia (no la mera coexistencia), en función de lo que deben hacer los ciudadanos para ser justos y consecuentes con una "ética cívica mínima" que defienda los derechos humanos de primera, segunda y tercera generación y propicie la formación en los valores que subyacen o emergen en el ejercicio de esos derechos.

\section{BiBLIOGRAFÍA}

ABDallah-Pretceille, M. (2001) La educación intercultural. Barcelona, Idea-Books.

Altarejos, F.; Rodríguez, A. y Fonttrodona, J. (2003) Retos educativos de la globalización. Hacia una sociedad solidaria. Pamplona, Eunsa.

Alvira, R.; Grimaldi, N. y HerRero, M. (1999) Sociedad civil. La democracia y su destino. Pamplona, Eunsa.

AnHeier, H.; Glasius, M. y Kaldor, M. (eds.) (2002) Global civil society 2001. Oxford, Oxford University Press.

ARENDT, H. (1974) La condición bumana. Barcelona, Seix Barral.

ATTINÀ, F. (2001) El sistema político global. Introducción a las relaciones internacionales. Buenos Aires, Paidós.

BECK, U. (1998) ¿Qué es la globalización? Falacias del globalismo, respuestas a la globalización. Buenos Aires, Paidós.

BERger, P. L. y HUNTINGTON, S. P. (2002) Globalizaciones múltiples. La diversidad cultural en el mundo contemporáneo. Buenos Aires, Paidós.

Borja, J. y CASTELLS, M. (1999) Local y global. La gestión de las ciudades en la era de la información (3. ${ }^{a}$ edición). Madrid, Taurus.

BRUNKHORST, H. (1995) Del estado nacional a la sociedad civil: ¿una perspectiva europea? Valencia, Episteme. 
JOSÉ MANUEL TOURIÑÁN LÓPEZ

SOCIEDAD CIVIL Y EDUCACIÓN DE LA CONCIENCIA MORAL

Castells, M. (2001) La galaxia internet. Reflexiones sobre internet, empresa y sociedad. Barcelona, Plaza Janés.

Castells, M.; Giddens, A. y Touraine, A. (2002) Teorias para la nueva sociedad. Santander, Fundación Marcelino Botín.

CoHEn, P. y otros (1999) Sociedad civil y teoría política. México, Fondo de Cultura Económico.

Colóm, A. J. (2000) Desarrollo sostenible y educación para el desarrollo. Barcelona, Octaedro.

CONSEJO ESCOLAR DEL ESTADO (2001) La convivencia en los centros escolares como factor de calidad. Construir la convivencia. Madrid, MEC.

Cortina, A. (1994) Ética minima. Madrid, Tecnos.

- (1995) La ética de la sociedad civil. Madrid, Anaya.

- (1998) Hasta un pueblo de demonios. Ética pública y sociedad. Madrid, Taurus.

DAHRENDORF, R. (1995) La cuadratura del círculo. Bienestar económico, cohesión social y libertad política. Madrid, Taurus.

- (2002) Después de la democracia. Barcelona, Crítica.

DeHESA, G. (2002) Comprender la globalización. Madrid, Alianza.

DIAZ-SALAZAR, R. (2002) Justicia global. La alternativa de los movimientos del Foro de Porto Alegre. Barcelona, Icaria Editorial.

Domínguez, I. y otros (2001) La realidad de las fundaciones en España. Análisis sociológico, psicosocial y económico. Santander, Fundación Marcelino Botín.

DRUCKER, P. (1993) La sociedad poscapitalista. Barcelona, Apóstrofe.

ECHEVERRía, J. (1999) Los señores del aire: Telépolis y el tercer entorno. Barcelona, Destino.

ESCÁMEZ, J. (1992) Estructuración y desestructuración de la comunicación interpersonal en contextos interculturales, en SEP. $x$ Congreso Nacional de Pedagogia, $\mathrm{n}^{\circ} 1,87-102$.

- (1999) Interculturalidad y fomento de actitudes interculturales, en Touriñán, J. M. y SANTOS, M. A. (eds.). Interculturidad y educación para el desarrollo. Santiago de Compostela, Instituto de Ciencias da Educación da Universidade de Santiago de Compostela, 247-262.

- (2003) Sociedad civil y evaluación de programas socio-educativos, en NúñEz, L. y. ROMERO, C. (eds.). Evaluación de políticas educativas. Actas del viI Congreso Nacional de Teoría de la Educación. Madrid, SITE-OEI, 145-151.

Ferguson, A. (1974) Un ensayo sobre la historia de la sociedad civil. Madrid, Centro de Estudios Constitucionales.

García Carrasco, J. (1992) Bases sociales y antropológicas de la educación intercultural, en SEP. X Congreso Nacional de Pedagogía, $\mathrm{n}^{\circ}$ 1, 15-37.

- (2002) Sociedad-Red, educación e identidad, en Gervilla, E. (coord.). Globalización, inmigración y educación. Granada, site, 13-92.

GarCía PASTOR, C. (2003) Segregación, integración e inclusión, Bordón, vol. 55, n 1, 9-26.

GidDENS, A. (1999) La tercera vía. La renovación de la socialdemocracia. Madrid, Taurus.

GIMENO SACRISTÁN, J. (2001) Educar y convivir en la cultural global. Madrid, Morata.

Gómez DacAl, G. (2003) Educación en contextos multiculturales, Revista de Ciencias de la Educación, no 193, 7-28.

Gray, J. (2000) Falso amanecer. Los engaños del capitalismo global. Buenos Aires, Paidós.

Hallak, J. (2003) Globalización, derechos humanos y educación, en NúÑEz, L. y ROMERO, C. (eds.). Evaluación de políticas educativas. Actas del viII Congreso Nacional de Teoría de la Educación. Madrid, SITE-OEI, 127-142.

HarcourT, W. (2003) The changing face of migration, Development, vol. 46, $\mathrm{n}^{\circ} 3,3-6$.

HEILBRONER, R. (1998) La crisis de visión en el pensamiento económico moderno. Buenos Aires, Paidós.

HunTINGTON, S. P. (2001) El choque de civilizaciones y la reconfiguración del orden mundial ( $6{ }^{2}$ edición). Buenos Aires, Paidós. 
JoRdÁN; J.; ORTEGA, P. y Mínguez, R. (2002) Educación intercultural y sociedad plural, Teoría de la Educación, n $^{\circ}$ 14, 93-119.

Jover, G. (2000) Educación y ciudadanía: el compromiso cívico de los jóvenes españoles, Teoría de la Educación. Educación y Cultura en la Sociedad de la Información, $\mathrm{n}^{\circ} 2$, www3.usal.es/teoriaeducacion.

- (2001) What does the Right to Education Mean? A Look at an International Debate from Legal, Ethical and Pedagogical Points of View, Studies in Philosophy and Education, vol. $20, \mathrm{n}^{\circ} 3,213-223$.

- (2002) Rethinking Subsidiarity as a Principle of Educational Policy in the European Union, en Ibáñez-Martín, J. A. y Jover, G. (eds.). Education in Europe: Policies and Politics. Dordrecht, Kluwer Academic, 3-22.

KLEINWÄCHTER, W. (2003) Global governance in the interformation age. Development, vol. 46, $\mathrm{n}^{\circ} 1,17-25$.

LEE, C. D. (2003) Reconceptualizing Race and Ethnicity in Educational Research, Educational Research, vol. $32, \mathrm{n}^{\circ} 5$, número monográfico.

LESSNOFF, M. H. (2001) La filosofía politica del siglo XX. Madrid, Akal.

LORENZO, R. y CABRA, M. A. (1991) Las fundaciones y la sociedad civil. Madrid, Cívitas.

MatTelart, A. (1998). La mundialización de la comunicación. Buenos Aires, Paidós.

MarTínez, M. y Puig, J. M. ${ }^{a}$ (1991) La educación moral. Perspectivas de futuro y técnicas de trabajo. Barcelona, Grao.

Mayor ZARAgoza, F. (1993) Papel de las fundaciones en el desarrollo de la sociedad civil. Santander, Fundación Marcelino Botín, $\mathrm{n}^{\circ} 2$.

MEDina, R. (1998) Los derechos humanos y la educación en los valores de una ciudadanía universal, Revista Española de Pedagogía, vol. LVI, $\mathrm{n}^{\circ} 211,529-560$.

Morin, E. (2002) ¿Una segunda mundialización?, Cuadernos de la Fundación M. Botín, $\mathrm{n}^{\circ} 2$.

Naval, C. (2002) Education for democratic citizenxhip in the new Europe: context and reform, European Journal of Education, vol. 37, $\mathrm{n}^{\circ} 2,107-128$.

Olveira, E.; Rodríguez, A. y Touriñán, J. M. (2003) Emigración, interculturalismo y legitimación cultural. Las sociedades gallegas en el exterior, Revista galego portuguesa de Psicoloxía e educación, $10, \mathrm{n}^{\circ}$ 8, 9-20.

ORDEN, A. de la (1999) Diversidad cultural y educación, en SEP. $x$ Congreso Nacional de Pedagogia, $\mathrm{n}^{\mathrm{0}} 1$, 9-12.

OrTEGA, P. (2001) La educación moral del ciudadano de hoy. Buenos Aires, Paidós.

Ortega, P.; Mínguez, R. y Saura, P. (2003) Conflicto en las aulas. Propuestas educativas. Barcelona, Ariel.

Otero Novas, J. M. (2001) Fundamentalismos enmascarados. Los extremismos de boy. Barcelona, Ariel.

Pérez Díaz, V. (1993) La primacía de la sociedad civil. Madrid, Alianza.

- (1996) Sociedad civil: una interpretación y una trayectoria, Isegoria, Revista de Filosofia Moral y Política, $\mathrm{n}^{\circ} 13,19-38$.

- (1997) La esfera pública y la sociedad civil. Madrid, Taurus.

- (2002) Globalización y libertad, Cuadernos de la Fundación M. Botín, $\mathrm{n}^{\circ} 2$.

PÉreZ SERRANO, G. (1994) Investigación cualitativa. Retos e interrogantes. Madrid, La Muralla.

- (1999) Educación para la ciudadanía. Exigencias de la sociedad civil, Revista Española de Pedagogia, $\mathrm{n}^{\circ}$ 213, 245-278.

POPPER, K. R. (1981) La sociedad abierta y sus enemigos. Buenos Aires, Paidós.

Puig, J. M. (1992) Minorías étnicas y educación democráticas: hacia el interculturalismo, en ORTEGA, P. Educación y democracia. Murcia, Caja Murcia, 117-134.

- (2003) Prácticas morales. Una aproximación a la educación moral. Paidós, Buenos Aires.

(C) Ediciones Universidad de Salamanca

Teor. educ. 15, 2003, pp. 213-234 
Roma, P. (2001) Jaque a la globalización. Cómo crean su red los nuevos movimientos sociales y alternativos. Barcelona, Grijalbo.

Romay BeCaría, J. M. (2002) Lecturas para estos tiempos. Sociedad abierta, globalización, inmigración, multiculturalismo. Santiago, Fundación Caixa Galicia.

Salamon, L. M. y otros (2001) La sociedad civil global. Las dimensiones del sector no lucrativo. Madrid, Fundación BBVA.

SARRAMONA, J. (1999) O desafío da educación intercultural para as minorías históricas, Revista Galega do Ensino, $\mathrm{n}^{\circ}$ 24, 247-268.

- (2002) Desafios a la escuela del siglo XXI. Barcelona, Octaedro.

SARTOR, G. (2001) La sociedad multiétnica. Pluralismo, multiculturalismo y extranjeros. Madrid, Taurus.

SEP (1992) Educación intercultural en la perspectiva de la Europa Unida. x Congreso Nacional de Pedagogía. Salamanca, Diputación de Salamanca.

SID (2000) Globalization and Knowledge Society: Expert Meeting. Santiago de Compostela, Fundación Caixa Galicia e Igaci.

SITE (2001) Conflicto, violencia y educación. Actas del xx Seminario Interuniversitario de Teoría de la Educación. Murcia, Cajamurcia (www.ugr.es/ site).

- (2002) Globalización, inmigración y educación. Granada, Seminario interuniversitario de Teoría de la educación.

STTGurtz, J. (2002) El malestar de la globalización. Madrid, Taurus.

TouriÑ́n, J. M. (1979) El sentido de la libertad en la educación. Madrid, Magisterio Español.

- (1983) El educador y su responsabilidad ante la legislación en la sociedad pluralista. Bordón, vol. xxxv, $\mathrm{n}^{\circ} 249,379-404$.

- (1997) La búsqueda de calidad en el desarrollo universitario y la definición de perfiles. Revista galega de cooperación científica iberoamericana, $\mathrm{n}^{\circ}$ 4, 40-61.

- (1999) Fines, valores, sistemas educativos y redes. Problemas de diversidad desde la perspectiva de la sociedad de la información, en Touniñán, J. M. y Santos, M. A. (eds.). Interculturidad y educación para el desarrollo. Santiago de Compostela, Instituto de Ciencias da Educación da Universidade de Santiago de Compostela, 39-69.

- (2000) Globalización y desarrollo: un reto de las políticas regionales de IDT. X Cumbre Iberoamericana de Jefes de Estado y de Gobierno. Ponencias de la Conferencia científica. La Habana, CYTED, 219-249. Y en Documentos de Economía, no 8, $70 \mathrm{pp}$.

- (2002) Educación y gestión cultural. Exigencias de la competencia técnica, Revista de Educación, número extraordinario, 179-198.

TOURIÑ́n, J. M.; RodRíguez, A. y Soto, J. (2000) Desarrollo, calidad de educación y nuevas tecnologías, Revista Galego-Portuguesa de Psicoloxia e Educación, vol. 5, n 4, 9-18.

TOURIÑ́́N, J. M. y SANTOS, M. A. (1999) Interculturalidad y educación para el desarrollo. Estrategias sociales para la comprensión internacional. Santiago de Compostela, Xunta de Galicia.

unESCO (1997) Nuestra diversidad creativa. Informe de la Comisión mundial de Cultura y desarrollo. Madrid, Unesco-SM. Fundación Santa María.

VALCÁRCEL, A. (2002) Ética para un mundo global. Una apuesta por el bumanismo frente al fanatismo. Madrid, Temas de hoy.

VARIOS (1998) Los derechos humanos y la educación, Revista Española de Pedagogía, vol. LVI, $\mathrm{n}^{\circ} 211$, número monográfico.

VÁzquez, G. (1994) ¿Es posible una teoría de la educación intercultural?, en Santos, M. A. (ed.). Teoria y práctica de la educación intercultural. Barcelona, PPU, 25-42.

Vidal Beneyto, J. (ed.) (2002) Hacia una sociedad civil global. Madrid, Taurus. 